\title{
OS TRABALHADORES RURAIS MIGRANTES NA CITRICULTURA PAULISTA: O CASO DA REGIÃO DE GOVERNO DE ARARAQUARA ${ }^{1}$
}

\author{
Giovana Gonçalves Pereira ${ }^{2}$ (NEPO/IFCH/Unicamp) \\ giovana.ggp@gmail.com
}

\begin{abstract}
RESUMO: Esse artigo se insere no contexto do Projeto Temático "Observatório das Migrações em São Paulo (FAPESP/CNPq)" e, objetiva a compreensão das migrações "permanentemente" temporárias de trabalhadores rurais migrantes piauienses para a colheita da laranja no interior do Estado de São Paulo. Compreendendo a migração como um fenômeno social multifacetado, optamos pela combinação de fontes de dados primárias e secundárias. Pautaremos nossa análise, portanto, através de entrevistas realizadas nos locais de destino e de origem, bem como, das informações disponibilizadas pelo banco de dados da Relação Anual de Informações Sociais (RAIS). O universo laboral, particularmente, em decorrência da possibilidade de acesso ao mercado de trabalho formal e aos direitos trabalhistas como o Seguro-Desemprego e o Fundo de Garantia, figura também como parte integrante do processo migratório de interesse. O ganho por produção na citricultura ocasiona, não obstante, cenários de competitividade entre os próprios colhedores. Sob esse contexto, nos propomos, por fim, construir um olhar conjunto frente aos espaços de origem e de destino visto que a migração se apresenta através da dinâmica social de ambas as localidades.
\end{abstract}

\footnotetext{
${ }^{1}$ Esse trabalho contém reflexões presentes na dissertação de Mestrado intitulada: "Entre o partir e o chegar: Os trabalhadores rurais em Matão/SP”. Campinas. Universidade Estadual de Campinas. 2015. Sendo financiado pela FAPESP, CNPq e pela CAPES.

${ }^{2}$ Bacharela e Licenciada em Ciências Sociais, Mestre em Demografia e aluna do Programa de PósGraduação em Demografia - Nível Doutorado no Instituto de Filosofia e Ciências Humanas da Universidade Estadual de Campinas. Sendo também integrante do Projeto Temático Observatório das Migrações em São Paulo (CNPq-FAPESP), coordenado pela Profa. Dra. Rosana Baeninger, sediado no Núcleo de Estudos de População "Elza Berquó” da Universidade Estadual de Campinas. Email: giovana.ggp@gmail.com
} 


\section{Introdução}

O entendimento do contexto de constituição da Região de Governo de Araraquara, pertencente à Região Administrativa Central, como palco das relações estabelecidas entre os trabalhadores rurais migrantes, alocados na colheita da laranja na última década, e o setor de exportação de commodities se assenta na apreensão de dois processos históricos: a modernização da agricultura na década de 1960 e a internacionalização da economia brasileira nos anos finais dos anos de 1990. Esse panorama viabilizou a constituição de espaços urbanos privilegiados (SASSEN, 1998 e BAENINGER, 2012) beneficiados pelo ciclo econômico cafeeiro (PACHECO, 1988) e posteriormente pelo início da cultura de citrus na região (ELIAS, 2003) e pelo o Proálcool (SILVA, 1999; BAENINGER, 1998).

A influência das agroindústrias citrícolas e sucroalcooleiras na composição da rede urbana regional se apresenta tanto a partir da divisão social e territorial do trabalho (CÔRREA, 2006) quanto pela distribuição espacial da população migrante dentro do espaço intra-urbano (VILLAÇA, 2002) dos municípios sejam estes configurados como cidades-dormitórios (SILVA, 1999) ou como cidades do agronegócio (ELIAS e PEQUENO, 2006).

Ao analisarmos a rede urbana da Região Administrativa Central (Figura 1), notamos o número significativo de cidades com populações abaixo de 20 mil habitantes. Essa característica já havia sido assinalada por Baeninger (1995) desde a década de 1970. A presença expressiva desses pequenos municípios simboliza, em distintos níveis, a importância dos espaços rurais na composição das especializações produtivas regionais (CANO, 1988), como a cana de açúcar e a laranja.

De mesmo modo temos à produção de pequenos produtores ou agricultores familiares que condizem com os métodos de produção convencional e, simultaneamente encontram-se casos mais recentes e pontuais, os quais mobilizam mercados e produções diferenciadas como a agricultura orgânica, a cachaça artesanal, as plantas ornamentais e culturas como as uvas e peras (PEREIRA, TROIANO e MACIEL, 2014). 
Figura 1: Distribuição Populacional na Região Administrativa Central por municípios em 2010 e Malha Rodoviária.

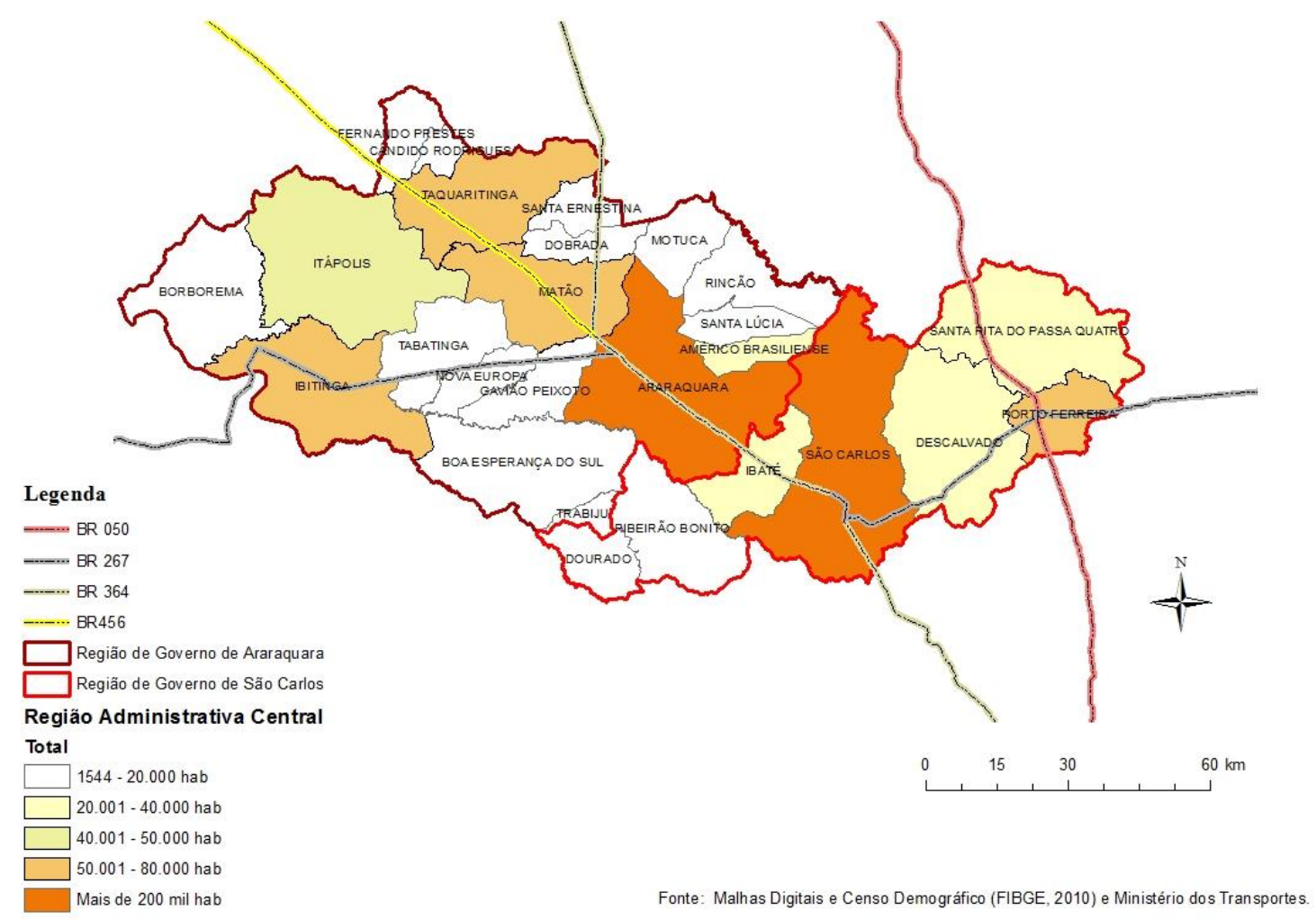

As cidades que despontam como mais populosas são: São Carlos (221.950 habitantes) e Porto Ferreira (51.400 habitantes) na RG de São Carlos e Araraquara (208.662 habitantes) e Matão (76.786 habitantes) na RG de Araraquara. Essas cidades encabeçaram o processo de urbanização de suas regiões de governo, principalmente, por serem beneficiadas por uma conjuntura histórica favorável ao desenvolvimento de atividades ligadas ao setor industrial no caso da RG de São Carlos e à agroindústria citrícola na RG de Araraquara.

Sob essa conjuntura, utilizaremos três conceitos norteadores para conduzirmos nossas inferências e reflexões sobre o presente cenário. O primeiro se relaciona à modalidade migratória (BAENINGER, 2012) apreendida na RG de Araraquara, mais especificamente no município de Matão/SP, denominada migração "permanentemente" temporária (SILVA, 2008), o qual se traduz pelas idas e vindas de trabalhadores rurais para o corte de cana e para a colheita da laranja no interior paulista. Esse conceito se apresenta, simultaneamente, através das características de renovabilidade e reversibilidade do fenômeno migratório (DOMENACH e PICOUET, 1998). O segundo conceito se refere 
à nova condição migratória, característica do século 21 , ocasionada pela existência da rotatividade migratória (BAENINGER, 2011 e 2012), ou seja, da coexistência entre os processos de emigração e de imigração em um mesmo espaço e período.

Finalmente, o terceiro conceito diz respeito à compreensão do local de destino como parte integrante dos circuitos espaciais de produção (SANTOS, 1998) da citricultura paulista, sendo amplamente beneficiado pela inserção de atividades agrícolas e agroindustriais em seu território. Desse modo, a urbanização e o crescimento econômico e demográfico do município de Matão/SP foram delineados a partir da implantação da Citrosuco Paulista em 1963 (ELIAS, 2003). Essas características, nesse sentido, compõem o quadro analítico do conceito de Cidade do Agronegócio (ELIAS e PEQUENO, 2006).

Com isso em vista, o presente artigo será subdivido em dois tópicos: o primeiro retratará as partidas e as chegadas da população migrante de Jaicós/PI para a cidade de Matão/SP, enquanto o segundo versará acerca das características do assalariamento rural na colheita da laranja.

\section{Os Trabalhadores Rurais Migrantes na Região de Governo de Araraquara: O caso de Matão/SP.}

\subsection{Considerações Iniciais}

A Região de Governo de Araraquara têm sua dinâmica econômica perpassada pela agroexportação desde sua formação (BAENINGER, 1995 e ELIAS, 2003). No século 19, com a produção do café, e, em meados da década de 1960 com a inserção dos complexos agroindustriais citrícola e sucroalcooleiro em seu território. Ocorreu pouco a pouco a expansão da cultura da laranja e da cana de açúcar em detrimento aos cafezais (SILVA, 1999). Destacando-se também os segmentos econômicos voltados para a indústria têxtil, de alimentos e de implementos agrícolas (PACHECO, 1988). Os principais centros-urbanos desta região de governo são os municípios de Araraquara e Matão.

Assim, a substituição das plantações de café pela cana de açúcar com o passar das décadas, ocasionou a consolidação do complexo agroindustrial sucroalcooleiro e posteriormente a instalação da primeira unidade de processamento de suco de laranja na região (BAENINGER, 1995; ELIAS, 2003 e MACIEL, 2013). Segundo Baeninger (1995), por meio de uma economia de base agrícola foi se configurando no passar do século 20 
uma região que concentrava complexos agroindustriais produtores de açúcar, álcool e cítricos.

Ao reconhecermos o município de Matão como centro-urbano que se especializou na produção de commodities e de máquinas e implementos agrícolas, devemos considerar todos os processos que interligam seu circuito de produção. Ou seja, desde o plantio da laranja por parte dos citricultores e da própria indústria processadora de suco concentrado até o consumo final da fruta 'in natura' e da adição do suco em refrigerantes e sucos concentrados naturais no mercado nacional e internacional.

De acordo com Corrêa (2004), o surgimento e a consolidação das atividades agrícolas e agroindustriais no município permitiram que ele se articulasse e se integrasse na economia global a partir da confecção de uma especialização produtiva vinculada à citricultura. Nessa conjuntura, o surgimento dos Complexos Agroindustriais na cidade resultou na transformação, em longo prazo, desta localidade em uma Cidade do Agronegócio (ELIAS e PEQUENO, 2006) preenchida por bairros de periferia (SILVA, 1999).

Desse modo, a compreensão da migração "permanentemente" temporária (SILVA, 1999) em Matão/SP pressupõe, não somente um entendimento da força de trabalho excedente como fruto da não-inserção ou da inserção parcial do local de origem no sistema capitalista (SINGER, 1976), mas também do papel deste dentro do capitalismo moderno. As modificações dos espaços intra-urbanos (VILLAÇA, 2001), nessa conjuntura, são de mesmo modo, primordiais.

A divisão espacial das cidades paulistas que tiveram seus espaços intra-urbanos redesenhados pela atuação das usinas e das indústrias processadoras de suco de laranja se manifesta, conforme aponta Silva (1999), através do "lugar dos bóias-frias" e do "lugar dos moradores da cidade". Em Matão, a população de trabalhadores rurais migrantes se distribui pela maior parte dos bairros da cidade, concentrando-se na zona alta, especialmente, nos bairros do Jardim do Bosque e do Jardim Popular.

O estabelecimento desses indivíduos nesses espaços se justificaria tanto pela vantagem de localização, que beneficia a circulação desses trabalhadores entre o município e as áreas rurais de seu entorno, caracterizando-os como trabalhadores rurais-urbanos (MELLO, 1976 e MACIEL, 2013). De mesmo modo, a concentração nesses espaços viabiliza a constituição e a fortificação das redes migratórias (SILVA, 2006 e VETORASSI, 2010). 
Dito isso, pretendemos a seguir delinear a centralidade do espaço migratório para a reconstrução desse fenômeno social como um processo heterogêneo e multifacetado. Focalizaremos, portanto, nossa exposição a partir do diálogo estabelecido entre o local de destino e de origem da modalidade migratória estudada (BAENINGER, 2012). Ou seja, dos municípios de Matão/SP e Jaicós/PI.

\section{2. "Os Piauí estão chegando": As idas e vindas dos trabalhadores rurais migrantes.}

Com o início da safra é perceptível na cidade paulista "murmurinhos" (ELIAS e SCOTSON, 2000) sobre a vinda dos piauienses. É comum, nesse sentido, ouvirmos frases como: "Os Piaú estão chegando". Nossa delimitação pelo estudo da migração de piauienses se fundamenta em resultados obtidos pelo pré-campo realizado em novembro de 2010, em acompanhamento do Serviço Pastoral dos Migrantes em Matão/SP.

Sob este contexto surgiu, em nosso estudo, a cidade piauiense de Jaicós/PI que possuía, em 2014, 18.585 habitantes (FIBGE, 2014). Localizada no sudoeste piauiense, ela se insere dentro da microrregião do Alto Médio Canindé, e possui uma economia pautada essencialmente no setor de serviços. Em $2010^{3}$, 52,82\% de sua população residente -9.527 habitantes - residia na área rural do município, a qual possuía em 2012, segundo os levantamentos de campo, aproximadamente vinte comunidades rurais ${ }^{4}$.

A maior parte da população rural do município de Jaicós/PI está alocada na agricultura familiar, baseada no cultivo de feijão, mandioca, milho, caju; na produção de leite e mel, e, na confecção de artesanatos (bolsas, chapeis, colares, cestos) com folhas de Carnaúba - árvore típica da região semi-árida nordestina. Pudemos perceber nas visitas à cidade nos meses de julho de 2012 e dezembro de $2013^{5}$ que a migração "permanentemente" temporária em Jaicós/PI é, em muitos casos, relacionada, como aponta o trabalho de Menezes (2009), às estratégias de reprodução social. Das quais se destacam o emprego local (em cargos municipais comissionados ${ }^{6}$, no pequeno comércio - lojas de

\footnotetext{
${ }^{3}$ Em 2010, a população da cidade era de 18.035 habitantes (Censo Demográfico, 2010)

${ }^{4}$ Baliza, Chácara dos Moraes, Morro da Pinicada, Saco da Serra, Jacú, Gameleira, Sítio, Poço do Pato, Santo Antônio, Esquisito, Paú do Enxuí, Várzea Queimada, Santana (I, II e III), Lagoa do Sabino, Senota, Bela Vista, Maria Preta, Bonito, Angilical dos Magos, Morro dos três irmãos, Barreiro e Fragá.

${ }^{5}$ As visitas à campo foram proporcionadas pela inserção dessa pesquisa no Observatório das Migrações em São Paulo.

${ }^{6} \mathrm{Na}$ cidade piauense, obtivemos relatos que correlacionavam a troca de votos por empregos públicos.
} 
departamento, mercearias, bancas nas feiras -), o artesanato, e, por fim a migração em busca de trabalho assalariado.

Existem, todavia, outros fluxos migratórios direcionados à colheita da laranja como os alagoanos. Contudo, a presença piauiense prevalece no discurso cotidiano dos agentes institucionais e dos moradores da cidade. Ademais, entendemos os trabalhadores rurais migrantes como categoria operacional resultante de transformações sociais e macroeconômicas, bem como, do surgimento de novos espaços migratórios (BAENINGER, 2012).

A população de trabalhadores rurais migrantes é parte constitutiva da mão de obra rotativa característica do capitalismo moderno. Sob essa conjuntura, o deslocamento desses trabalhadores entre espaços rurais e bairros rurais-urbanos (SILVA e MELO, 2011) para um espaço urbano altamente tecnológico inserido na lógica de produção global, pode ser entendido através das inferências de Baeninger (2012) acerca da rotatividade migratória e seu vínculo com a expansão do capitalismo por intermédio da circulação de mercadorias, pessoas e capital, contexto que constitui um excedente populacional rotativo. Portanto:

\begin{abstract}
A rotatividade da mão-de-obra nos processos migratórios - via migrações contribuirá para atender as demandas e custo da força de trabalho nos locais de chegada e de partida. Quanto mais as regiões vão inserindo seus segmentos na economia internacional, mais propensas se tornam essas áreas para experimentarem a rotatividade de suas populações, com a fluidez da mão-deobra nos setores dessa produção (BAENINGER, 2012, p. 82).
\end{abstract}

A partir dos anos finais da década de 1990 e do início dos anos 2000 intensificaram-se as migrações de piauienses para o município paulista. Entretanto a cidade paulista já era conhecida em Jaicós/PI desde os anos finais da década de 1960 com a chegada de máquinas de arado e implementos agrícolas da Baldan e da Marchesan, assim como, dos produtos da Predilecta e do açúcar agranel. Eduardo ${ }^{7}$, cerca de 50 anos, descendente de indígenas e morador do "interior" nos contou um pouco dessa história:

A primeira pessoa que foi daqui pra Matão foi na década de 1960, 1968 por aí. Ai depois foi Vitorini mais meu cunhado. Ai depois chegou mais um povo e foi descobrindo, descobrindo. Mas foi pra 68 pra 70, mais ou menos. (...) Naquela época o pessoal ia pra Baldan, ai depois pra TATU [Marchesan]. Ai quando chegava aqui pra comprar um arado, eles diziam que queria um do peixe, porque depois por conhecimento descobriram o que era o símbolo do peixe né? Ai quem ia comprar o produto da Marchesan queria um do TATU porque "era o melhor que tinha". Isso facilita o costume que era [assimilar a empresa] do TATU. (...) Inclusive se você anda por interior ai, tem muita coisa, muito produto que vem de Matão. Vem direto, vem o açúcar, muitos implementos

\footnotetext{
${ }^{7}$ Todos os nomes dos entrevistados foram modificados com o intuito de preservarmos suas identidades.
} 
agrícolas vêm de Matão, vem compressor da Bambozzi (...) Todo mercado que você chegar aqui você vai ver, no comércio você vai encontrar os produto do Tatu, da Predilecta, [inaudivel] tem o doce também, tem a goiabada, tudo os produto da Predilecta quase tem. [Entrevista realizada em Jaicós no dia $16 / 12 / 2013]$

A exposição de Eduardo nos trouxe um elemento chave para a compreensão da migração "permanentemente" temporária (SILVA, 2008a e 2008b) para Matão/SP. A circulação de mercadorias e a preexistência de uma rede migratória entrelaçada com o emprego urbano em fábricas de implementos agrícolas possibilitaram um contato preliminar da população jaicoense com a cidade paulista. Conjuntamente, destaca-se a importância da fortificação de laços com a origem, como: as comidas típicas enviadas de Matão/SP ou de Jaicós/PI, os cuidados com a residência daqueles que migraram na origem e a obtenção de moradia no destino.

As redes de relações dessa população perpassam ambos os municípios envolvidos na dinâmica migratória. Além disso, ocorre a coexistência de distintos processos e ciclos migratórios (SILVA, 2008c) nesses locais. Em Matão/SP observamos a presença de paranaenses, piauienses, paraibanos e mineiros na composição da rede migratória dos trabalhadores rurais migrantes, sendo responsáveis pelo aluguel das moradias ${ }^{8}$, pela arregimentação e pelo agenciamento da viagem destes de Jaicós/PI para o interior paulista.

Aferimos também que em um primeiro momento a população jaicoense migrante, essencialmente masculina, concentrou-se, em Matão/SP, nos pequenos barracos e cômodos localizados nos bairros Jardim do Bosque e Jardim Balista. O processo migratório de interesse se iniciou na década de 1960, portanto, com a migração individual, a priori masculina. Posteriormente constataram-se migrações familiares, já no contexto do trabalho rural-urbano (MACIEL, 2011), as quais ocasionaram a incidência das "casas fechadas" nas comunidades rurais do município piauiense.

O fenômeno das "casas fechadas" se apresenta através da ausência da população migrante nos espaços rurais de Jaicós/PI, conhecidos como "interior". A manutenção da casa daquele que está ausente é realizada, normalmente, pelas mulheres:

Dona Lúcia: Quando ela não vai [a filha que está no Piauí], ela fica só em casa (...) ela faz a limpeza lá em casa, que eu mandei a minha irmã entregar a chave porque a minha irmã [que cuidava anteriormente da casa] tava limpando também a casa da minha filha e é meio longe. Em um lugar chamado Antonino,

\footnotetext{
${ }^{8}$ A obtenção de moradia ocorre, em geral, pelo intermédio de contratos de aluguéis informais estabelecidos entre o migrante a o dono do imóvel. Não foram raros os casos em que as moradias correspondiam à pequenos cômodos e com a divisão do banheiro e da lavanderia.
} 
não sei se vocês passou de lá. [Entrevista realizada em 13/07/2012, em Matão/SP]

É fundamental que a residência mantenha-se limpa e cuidada durante a ausência de seu morador. Desse modo, ela se mantém como presença social dos que se ausentaram. Com o retorno da safra no mês de dezembro, as casas são abertas e, em geral, reformadas ganhando novas cores e azulejos, assim como, tem seu interior preenchido por móveis e eletrodomésticos provindos do "trabalho da laranja". Como podemos visualizar pelo enxerto de entrevista a seguir:

\begin{abstract}
Ana: Tudo que eu tenho de casa é de Matão, então eu valorizo muito esse serviço porque sem esse serviço da laranja eu não teria minha geladeira boa, que eu tenho vocês vão vê lá. Eu tenho um guarda roupa bom. Tenho a minha cama boa. Eu tenho meu armário bom, eu tenho minha mesa boa. Eu tenho tudo na minha casa, de móvel bom sabe? Mas, eu não tenho nada aqui. Nem uma cadeira pra sentar, eu não tenho. Tenho minha casa boa. Que eu posso recebe cem pessoas. Tem uma varanda boa (...) Tenho minha propriedade cercadinha lá. E se não fosse Matão, eu não teria nada disso. O que eu tenho dentro da minha casa [Entrevista realizada em 13/06/2012, Matão/SP].
\end{abstract}

A materialização do ganho no trabalho da safra se relaciona, simultaneamente, à constituição da migração como prática e distinção social (SILVA, 2008c). Nesse sentido, o "possuir" ou "ter" algo "de Matão" simboliza a concretização do "sucesso" da migração. Tais transformações ocorrem graças ao acesso ao assalariamento temporário vinculado, em nosso caso, à um mercado de trabalho formal. Pretendemos, assim, demonstrar algumas características acerca do assalariamento rural no próximo item.

\title{
2. O Assalariamento na Citricultura Paulista
}

\subsection{Condições de Trabalho}

A cadeia produtiva da citricultura paulista gera em média um emprego temporário para cada 9 hectares (NEVES ET AL, 2010). A presença de processos produtivos altamente tecnológicos e automatizados na indústria processadora de suco concentrado de laranja se contrasta com a ampla empregabilidade de mão de obra na etapa da colheita. Estima-se que “(...) cada emprego direto no campo gera dois indiretos ao longo da cadeia (...)" (NEVES ET AL, 2010, p. 66).

Em 2013, de acordo com a Relação Anual de Informações Sociais, foram gerados 8.930 vínculos empregatícios de trabalhadores agrícolas da fruticultura na RG de Araraquara, dos quais $62,90 \%$ eram masculinos e $37,10 \%$ femininos. Desses, 4.449 
vínculos se relacionam às admissões realizadas entre os meses de junho e julho, período no qual se iniciam, em geral, as colheitas na região. O ganho médio salarial referente à 67,34\% dos vínculos empregatícios dessa categoria ocupacional foi entre $\mathrm{R} \$ 670,65$ e $\mathrm{R} \$$ 1.341,90. Em geral, um colhedor de laranja costuma colher entre três à oito sacolões (bags) diários, cada sacolão pode pesar em média 600 kg (MOLIN e MASCARIN, 2007).

O ganho médio de um colhedor na safra 2012/2013, segundo as entrevistas realizadas em campo, foi de $\mathrm{R} \$ 0,47$ por caixa colhida, sendo variável de acordo com a qualidade da fruta e do pomar. Um pomar considerado "bom" para a colheita, segundo os trabalhadores rurais migrantes, é o que possui um valor mais baixo do que um pomar "ruim", pois necessita de menos esforço físico para a realização da colheita, mas permite um maior rendimento do trabalhador. Assim, um "bom pomar" é definido pelo pé de laranja baixo, carregado e que nem sempre necessita da utilização de escada. Enquanto que um pomar "ruim" é ilustrado pela maior altura do pé da laranja e pelas eventuais dificuldades no momento da colheita.

Existem categorias de trabalhadores rurais na citricultura definidas segundo a produtividade do colhedor. O "Aranha" é representado por sua baixa produtividade, sendo visto como um "colhedor ruim", enquanto que o "Pai" ou "Mãe" da turma são aqueles que conseguem produzir em torno de dez big bags $^{9}$, ou seja, de 100 a 150 caixas de laranja.

Ademais, existem importantes atores sociais envolvidos na arregimentação dos colhedores de laranja no interior do Estado de São Paulo. Nesse caso, a compreensão do "gato" - responsável pela contratação e arregimentação da mão de obra no campo e presente em distintos estudos que envolvem a temática migração e trabalho rural assalariado (SILVA, 1999 e 2008; BARBOSA e ALVES, 2008 e 2009; MENEZES, 2009; VETORASSI, 2010, WANDERLEY, 2011; MACIEL, 2013) - é essencial para entendermos a relação que se estabelece entre trabalhadores rurais migrantes e a empresa contratante.

A contratação para a colheita da laranja costuma se efetivar, segundo os dados de campo e estudos anteriormente desenvolvidos sobre a categoria (SILVA, 2008c; BARBOSA e ALVES, 2008 e 2009 e MACIEL, 2013), através dos empreiteiros. Estes são, em geral, antigos trabalhadores rurais e, muitas vezes os responsáveis pelo transporte dessa mão de obra entre a área urbana e as propriedades rurais (SILVA, 1999; VETORASSI,

\footnotetext{
${ }^{9}$ De acordo com as entrevistas exploratórias realizadas em Matão/SP, os "big bags" podem ser conhecidos como "sacolão". Sendo uma espécie de grande bolsa na qual os trabalhadores depositam sua colheita. Cada big bag corresponde em média à 20 caixas de laranja.
} 
2010; MACIEL e BAENINGER, 2011). Outra figura importante na dinâmica laboral da citricultura é o fiscal de turma, responsável pela contabilização das horas trabalhadas e da produção dos colhedores ${ }^{10}$.

Rubem, um empreiteiro conhecido na cidade de Matão/SP, explicou-nos em maio de 2012 sobre a "inscrição" das pessoas para a colheita da laranja. Cuja efetivação se dá ora a partir de uma "ficha" da empresa distribuída entre os trabalhadores no momento da chegada destes na Rodoviária dos Piauí ${ }^{11}$, ora pelo contato destas pessoas com o empreiteiro via telefone celular. Em um momento posterior ao preenchimento da ficha, o empreiteiro, em conjunto a um representante da área de recursos humanos da empresa, visita a residência destes trabalhadores com o intuito de verificar as "condições" físicas e higiênicas do local, característica condicionante, mas não determinante para a contratação final $^{12}$.

Os trabalhadores agrícolas na fruticultura em Matão/SP são contratados, em sua integridade, para trabalharem de 41 a 44 horas semanais (RAIS, 2012), isto é, de 7 a 8 horas por dia. A jornada de trabalho dos colhedores de laranja se inicia na madrugada e encerra-se nas horas finais da tarde, ou seja, das $05 \mathrm{hrs}$ às $18 \mathrm{hrs}$. A cidade paulista possuía, em dezembro de 2012, 8.829 vínculos ativos atrelados à categoria ocupacional de Trabalhadores Agrícolas da Fruticultura, desses 37,68\% eram referentes aos vínculos femininos e $62,31 \%$ aos masculinos.

É comum a existência de uma divisão sexual de tarefas na colheita. Em geral, as mulheres ficam responsáveis por "catarem" as laranjas e os homens por derrubarem ela do pé, normalmente, se utilizando de escadas. Contudo, existem casais que trabalham separadamente e juntam seus ganhos somente no final de cada mês. Todavia, cabe destacar que a maior abertura à mão de obra feminina é, muitas vezes, permeada pela dominação masculina frente à decisão da mulher em acompanhar o marido e trabalhar na safra.

Assim, além desta ficar responsável pela manutenção da ordem doméstica, pelo cuidado das crianças e pela limpeza da casa, é ela também a responsável pela preparação da comida que será levada à roça e por lavar os uniformes de trabalho. Em somatória, a

\footnotetext{
${ }^{10}$ Como já apontavam os estudos de Maciel (2012), os trabalhadores da citricultura, normalmente, não tem conhecimento de quem realmente os contrata. Era comum em suas narrativas, eles explicarem que haviam sido contratados pelo fazendeiro do Fischer em referência à Citrosuco (Grupo Fischer).

${ }^{11} \mathrm{O}$ local conhecido popularmente como "Rodoviária dos Piauí" é uma agência de viagens clandestina localizada no Jardim do Bosque. Sendo resultado de uma parceria iniciada em meados de 2000, um paranaense - dono do imóvel e comerciante - e a agência jaicoense Chiq-Tour.

${ }^{12}$ Em janeiro de 2013 fui convidada pela Citrosuco para uma reunião com o departamento de Recursos Humanos Agrícola no qual fui informada que parte da preocupação acerca das moradias se baseava na tentativa de certificação da empresa.
} 
presença feminina, desde que maior de idade, tende a potencializar os ganhos familiares. Podemos observar essa inferência de forma mais evidente na fala de Lourdes, excolhedora, a seguir:

Ai no Matão, homem e mulher trabalha, ai os homem acha mais melhor. Porque levava as mulher, assim, de modo a trabalhar pra ajudar, ajudava e lavava a roupa. E, eles indo só, eles eram forçados a lavar a roupa deles. Ai se ele pode levar mulher, eles acha mais melhor. Porque levando lá as mulher, elas sempre trabalha. Cuida da casa. (...) Em São Paulo, eles achava ruim a modo de paga alguém pra lavar a roupa, porque homem num é sempre que lava a roupa né? (...) Tem deles que não leva, assim, sabe [mulher] de menor, assim é difícil de levar. Porque é mulher de menor, ai não pode trabalhar, eles que leva as mulher que já tem a idade pra trabalha na roça mais eles. (...) Trabalhava, assim, de domingo e de sábado, lavava a roupa e arrumava a casa. (Entrevista realizada em Jaicós/PI no dia 15/12/2013).

Nessa conjuntura, temos que mesmo se tratando de um mercado de trabalho que permite uma maior participação da mão de obra feminina, em comparação à cultura canavieira, o assalariamento rural na citricultura é fundamentado no mercado laboral masculino, o qual articula como salienta Silva (2008b), os territórios de origem e de destino.

Já em referência ao tempo médio de emprego, temos que $85 \%$ (7.586) dos 8.140 desligamentos ocorreram em um período inferior à um ano trabalhado. Sendo 4.621 destes realizados no período de 2 a 5,9 meses e 2.965 entre 6 e 11,9 meses. Outro fator interessante é que o primeiro semestre do ano de 2012 concentrou $69 \%$ dos desligamentos daquele ano.

Ao investigarmos os motivos de desligamento (Tabela 1), notamos que a maior parte destes ocorreu, no primeiro semestre, em decorrência da demissão sem justa causa vinculada ao termino da safra que costuma ocorrer entre os meses de janeiro e fevereiro. Já no segundo semestre, os desligamentos sem justa causa representam, em muitos casos, o retorno desses trabalhadores ao local de origem sem necessariamente completarem o anosafra. 
Tabela 1: Vínculos Inativos por Motivo e Semestre de Desligamento dos Trabalhadores Agrícolas da Fruticultura, em Matão/SP, 2012.

\begin{tabular}{lcc}
\cline { 2 - 3 } \multicolumn{1}{c}{ Motivo de Desligamento } & \multicolumn{2}{c}{ Semestres } \\
& $\mathbf{1}^{\mathbf{0}}$ & $\mathbf{2}^{\mathbf{0}}$ \\
\hline Demissão com Justa Causa & 22 & 120 \\
Demissão sem Justa Causa & 5.193 & 381 \\
Término Contrato & 245 & 152 \\
Desligamento sem Justa Causa & 176 & 1.843 \\
Falecimento & 2 & 6 \\
\hline Total & $\mathbf{5 . 6 3 8}$ & $\mathbf{2 . 5 0 2}$ \\
\hline
\end{tabular}

Fonte: Relação Anual de Informações Sociais, 2012. Observatório das Migrações em São Paulo (FAPESPCNPq/NEPO-Unicamp).

Os desligamentos ocasionados por motivo de falecimento ilustravam 5 casos de indivíduos da faixa etária de 25 a 39 anos, 2 casos pertencentes ao grupo etário de 50 a 64 anos e 1 caso ao grupo de 65 anos ou mais. Desses 2 eram mulheres e 3 homens de 25 a 39 anos, e os demais eram homens (vide Tabela 1). Todos os falecimentos ocorreram, de acordo com a base de dados da Relação Anual de Informações Sociais de 2012, em empresas que possuíam CNPJ e com mais de mil funcionários, o que representariam, potencialmente, as indústrias processadoras de suco, responsáveis por parte majoritária das contratações.

A discussão acerca dos acidentes e mortes causados pela imposição de um intenso ritmo de produtividade dentro dos laranjais e canaviais paulistas já foi explorada em outros trabalhos (ALVES, 2006 e SILVA, 2008c). Para Silva (2008c), o tema se apresenta, entretanto, imbricado em possíveis constrangimentos relacionados ao receio dos trabalhadores rurais em receberem retaliações por suas denúncias, por parte dos detentores do processo produtivo.

No caso da laranja as principais queixas encontradas se enquadram na má qualidade dos equipamentos de proteção individual (EPI), particularmente, dos óculos de proteção que tendem a embaçar conforme são feitos os movimentos de derrubada da laranja, os acidentes provocados pelo uso de escadas, casos de cegueira ocasionados por galhos, picadas de cobra, além de o uso de venenos pesticidas como o carbendazim que acarreta, muitas vezes, alergias de pele e problemas respiratórios. Foi constatada também uma morte oficialmente divulgada $^{13}$ de um fiscal de turma em razão do uso de veneno ${ }^{14}$. A comoção

\footnotetext{
${ }^{13}$ Maiores informações: Trabalhador rural morre por envenenamento (10/10/2012):
} 
da população jaicoense ocasionou, inclusive, a confecção de camisetas com seu rosto estampado.

Figura 2: Alergia de pele ocasionada, segundo ex-colhedor, pelo uso de veneno em Matão/SP.

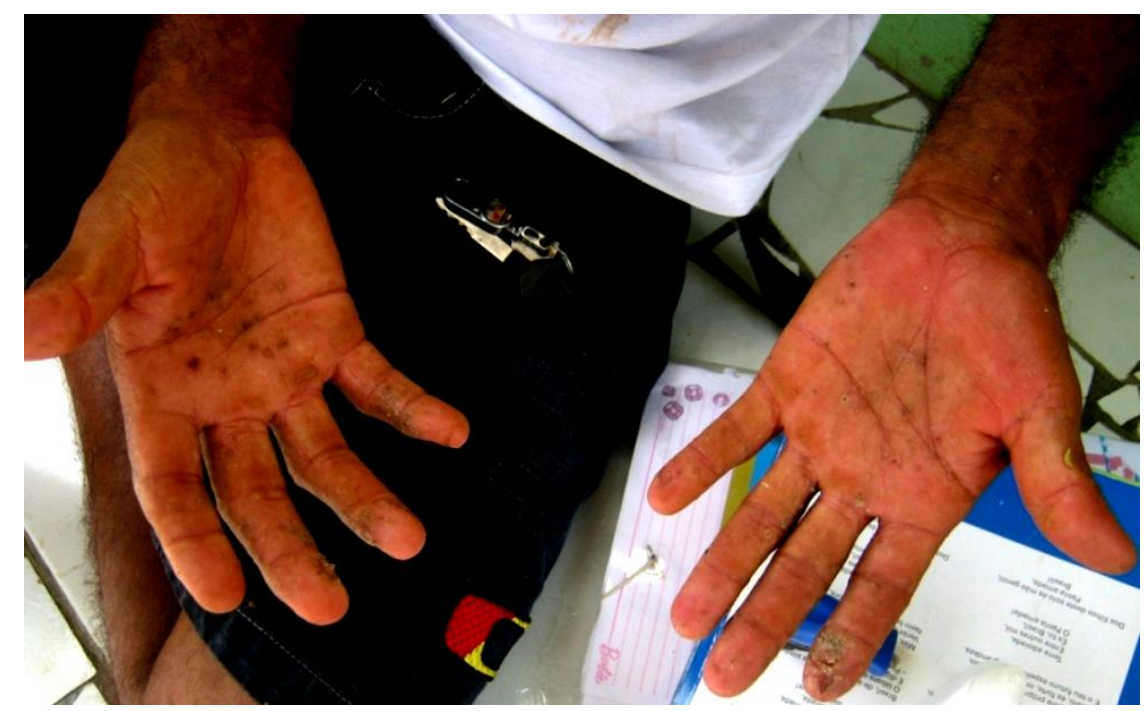

Fonte: PEREIRA, G.G. e MACIEL, L.M. Banco de Imagens do Observatório das Migrações em São Paulo (2013).

Os trabalhadores são orientados a se higienizarem antes de iniciarem os trabalhos, esse procedimento envolve a lavagem das mãos e dos pés em uma água que alguns colhedores afirmam se tratar de "veneno". Segundo as informações captadas no Hospital Estadual Floriza Silva, em Jaicós/PI, os primeiros indicativos da intoxicação por veneno costumam ser a falta de ar e uma dor na região dos rins. A utilização do carbendazim começou a ser restringida nos laranjais paulistas, em 2012, após o embargo do governo norte-americano em decorrência de resquícios desse fungicida no suco de laranja concentrado exportado ao país ${ }^{15}$.

Apesar de tais contingências, o assalariamento na citricultura é bem visto pelos trabalhadores em geral. Como aponta Silva (2006) por se tratar de um "trabalho aberto", a colheita da laranja se apresenta mais valorizada pelos trabalhadores em relação ao trabalho no qual há um maior controle sobre o tempo trabalhado. Ser "patrão de si mesmo" foi um dos motivos mais destacados nos discursos dos trabalhadores rurais entrevistados. A

\footnotetext{
http://www.saibaja.com.br/tv-matao/noticia/1430-matao-trabalhador-rural-morre-por-envenenamento

${ }^{14} \mathrm{O}$ veneno é aplicado, segundo os trabalhadores, por um trator e possui um forte odor que lembra, para alguns, o cheiro de inseticidas para o combate às formigas.

${ }^{15}$ Matéria veiculada no portal on-line do G1: "Citricultores de SP devem substituir fungicida proibido pelos EUA” (http://g1.globo.com/economia/agronegocios/noticia/2012/02/citricultores-de-sp-devem-substituirfungicida-proibido-pelos-eua.html)
} 
preferência pelo trabalho na laranja frente aos empregos urbanos é presente, principalmente, nos discursos das colhedoras, como vemos na fala de Maria:

É assim, né? É produção. Lá ninguém fala assim: "Ah o serviço ta errado", "Esse serviço é assim”, num tinha entendeu? Lá era por conta minha. Ela [empreiteira] me ensinava e saia. Não ficava no meu pé. Eu acho bom, é isso aí que ninguém ficava me enjoando. Você fazia o que você podia fazer. [Entrevista em Jaicós/PI, no dia 10/12/2013; grifos nossos]

O destaque em negrito se refere à uma comparação ao seu antigo trabalho em casa de família como empregada doméstica. Assim, para essa ex-colhedora o trabalho na colheita da laranja simbolizava que ela mesma ditava seu próprio ritmo de rendimento, além de aparentar um ambiente de trabalho sem uma supervisão constante. Entretanto, o ganho por produtividade também gera uma concorrência pela maior produção entre os próprios colhedores:

\begin{abstract}
Maria: Só que na laranja é assim, na laranja o povo é muito ambicioso, se tu tiver com um sacolão, faltando uma sacola pra enche e eu tive no chão, ele não dá. Se você tiver, cê num dá. Isso é muito ambicioso. Só que pra si sabe? Tem olho grande! Se você disser quanto foi que você tirou no holerite, eles fica tudo com olhão. Não pode dizer quanto você tirou. Ele são ambicioso. Na laranja é.

Entrevistadoras: Mas, pra querer tirar mais?

Maria: Exatamente pra querer tirar mais que você. Sempre você não quer ficar por baixo, quer tirar mais. E é todo mundo. A gente também é assim, porque tem gente que é assim se você tira pouco eles vai espalhando que você não colhe, que você é aranha (Entrevista em Jaicós/PI, no dia 10/12/13).
\end{abstract}

Alves (2006), em seu estudo sobre os cortadores de cana no interior paulista, destaca que quando os trabalhadores recebem por produção e tem seu pagamento associado à sua produção diária se transfere ao trabalhador a responsabilidade do ritmo do trabalho, que é a atribuição do capitalista. $\mathrm{O}$ autor ainda pondera que a quantidade de rendimento do trabalhador depende, exclusivamente, de sua força e habilidade que não são, necessariamente, condicionadas às necessidades de produção do empregador, em nosso caso, das indústrias processadoras de suco.

A fala de Maria mostra a competitividade e fiscalização coletiva que cada colhedor vivencia diariamente, as quais ocorrem através de brincadeiras jocosas e apelidos aos maus colhedores (Aranha) e bons colhedores (Pai da turma). Esse cenário corrobora para a fortificação do ritmo de produtividade entre os integrantes da turma de colhedores.

Ainda pontuamos que se fez necessário compreender, no momento da pesquisa, a importância do seguro-desemprego na tomada de decisão entre o momento de partida e da 
chegada em Jaicós/PI ${ }^{16}$. Além da preocupação de como se organizará a dinâmica intrafamiliar entre aqueles que ficam e os que se ausentam fisicamente (MENEZES, 2002, SILVA, V. 2006 e SILVA, M. 2008a e 2008b), a obtenção desse beneficio social promove a reorganização do tempo de estadia no local de destino.

É comum, portanto, a presença do "seguro" no discurso dos entrevistados, mesmo nos casos em que a nossa entrevista não planejava inicialmente ser conduzida para o universo do trabalho. O seguro era visto como parte estruturante das condições que delimitam a percepção de "sucesso" da migração no momento do retorno e também é ele quem mediava a vivência desses indivíduos em relação aos seus próprios direitos sociais e civis. A narrativa de Ana, 30 anos, colhedora de laranja há mais de três safras em Matão/SP, nos reforça a importância do seguro-desemprego no momento da tomada de decisão:

\begin{abstract}
Meu irmão me ligou e disse: Ana, você não quer vir pra Matão pra trabalhar na laranja e conseguir o seguro-desemprego? E minha mãe já tinha trabalhado em São Paulo e pegado o seguro-desemprego, minha mãe e meu pai falavam muito que pegar o seguro-desemprego era uma das melhores coisas porque era um dinheiro, né? Que a gente tinha direito. Seguro-desemprego e tudo. Ai eu digo: meu sonho é pegar esse seguro! Então eu vou. (Entrevista realizada em Matão/SP, no dia 13/07/2013: Grifos meus).
\end{abstract}

Ocorria, inclusive, uma sensibilização da população quando algum conhecido não conseguia por questão de alguns dias de trabalho obter o seguro. Ou seja, a não garantia de renda fixa pelos meses vividos no entre-safra no local de origem. Temos também a centralidade das plantações de "fundo de quintal" para a manutenção temporária dessas pessoas no período entressafra ou na ausência de possibilidade de emprego formal na colheita da laranja.

Os fundos de quintais em Matão/SP abrigam plantações, em sua maioria, de goiaba e laranja. Todavia, trabalhar informalmente no destino, seja em empregos urbanos (construção civil e doméstica), seja em empregos rurais não é bem visto pelos

\footnotetext{
${ }^{16}$ As modificações anunciadas pela equipe econômica federal enunciam o aumento de carência para solicitação do seguro-desemprego que passaram de 6 para 18 meses nos últimos 24 meses trabalhados na primeira solicitação. Já na segunda solicitação o prazo passou de 6 para 12 meses nos últimos 16 meses trabalhados, e na terceira manteve-se a carência de 6 meses. As mudanças, contudo, ainda carecem de aprovação no Congresso Nacional. Para maiores informações: HAUBERT, M. "Dilma admite negociar com congresso mudanças em benefícios trabalhistas". Folha de São Paulo Online. 20/02/2015.

<http://www1.folha.uol.com.br/poder/2015/02/1592332-dilma-admite-negociar-com-congresso-mudancasnos-direitos-trabalhistas.shtml> e, CRUZ, V.;SOFIA, J. "Governo vai recuar em mudanças no segurodesemprego".Em Folha Mercado. 27/01/2015.

< http://www1.folha.uol.com.br/mercado/2015/01/1580972-governo-vai-recuar-em-mudancas-no-segurodesemprego.shtml>
} 
trabalhadores migrantes, pois não existem garantias legais de recebimento do salário ou do seguro. Por fim, delinearemos a seguir sobre o perfil encontrado nessa categoria ocupacional.

\subsection{O Perfil do Trabalhador Rural Migrante na Citricultura}

Os perfis dos trabalhadores rurais migrantes alocados na etapa da colheita da laranja em Matão/SP se correlacionam ao local de residência do indivíduo na origem. Nessa conjuntura, os moradores dos bairros-rurais de Nossa Senhora das Mercês e do João Melé ${ }^{17}$, ambos constituídos por famílias de baixa renda, constituem uma população migrante que se emprega, além da colheita da laranja em Matão/SP, ora nos pequenos comércios, ora em empregos públicos graças à prática de troca de votos existente em Jaicós/PI. A qual figura como parte da estratégia de permanência destes nos locais de origem. Todavia, muitas vezes, o acesso a essas oportunidades de emprego não é encadeada a entrada no mercado de trabalho formal.

Já os moradores da área rural, quando pequenos proprietários, trabalham com o plantio do caju, da mandioca, do milho, do feijão de corda, com a produção de mel e confecção de artesanatos com a folha de carnaúba. O retorno para Jaicós/PI é, portanto, realizado preferencialmente, no mês de dezembro não somente pelo final da safra da laranja, mas também pelo início da estação de plantio que costuma ser procedido por um período de chuvas entre dezembro e janeiro, o qual os moradores denominam como "inverno". A ocorrência do inverno é fundamental para a manutenção econômica desse município que se localiza no semi-árido nordestino.

Captamos também duas composições de população migrante às quais se correlacionam à migração individual ou familiar. Quando a migração é realizada de maneira individual, o migrante é reconhecido socialmente no caso dos homens como "peão" e no caso das mulheres como "solteira". Contudo, a ocorrência de uma migração individual não predispõe necessariamente a inexistência de um não vínculo com uma unidade familiar. Sobre a migração de solteiras temos o relato de Fabiana, 36 anos, moradora do interior:

\footnotetext{
${ }^{17}$ Esses bairros podem ser denominados bairros-rurais por se apresentarem a partir da continuidade do espaço rural no espaço urbano (SILVA, 2008b; MELO e SILVA, 2011). Eles foram formados há cerca de vinte anos com a vinda de antigos residentes do interior jaicoense para a cidade.
} 
Fui [sozinha], tinha assim mais as colegas da gente. Falavam assim que lá [Matão] é bom, que o trabalho lá é bom, "vamos que eu te apoio até tu arrumar um lugar pra tu morar”. Ai eu fui. (...) A primeira vez eu morei lá pra cima do Popular, na primeira vez. Ai, na segunda eu morei lá pro centro. Porque lá no centro eu fui na casa do patrão mesmo. (...) Porque o patrão tem a casa própria dele morar e a casa própria pros peão, pra recebe as pessoas, tem a casa dos homem, a casa das mulher. [Entrevista realizada em Jaicós/PI no dia $11 / 12 / 2013]$.

Como visualizamos pela fala de Fabiana a contratação de peões e solteiras se relaciona aos alojamentos separados segundo o sexo. Além disso, segundo a mesma, o pagamento pelo quarto individual era de $\mathrm{R} \$ 100$ mensais que deveriam ser pagos ao empreiteiro. Conjunturalmente, os processos migratórios atrelados à colheita da laranja se correlacionam as condicionantes específicas dos espaços de origem dos indivíduos, sendo acompanhadas por seletividades migratórias expressas, particularmente, pelo sexo e pela faixa etária, e que são condizentes à realidade social encontrada em cada 'interior' ou bairro rural.

Sob esse contexto, pudemos observar nas cinco comunidades rurais visitadas que a migração, mesmo quando não vivenciada pela comunidade de forma intensa, como no caso de Croasal, se apresenta como parte fundamental do cotidiano desses indivíduos. Na Baliza e no Esquisito, a migração direcionava-se, no momento da pesquisa, basicamente para o município de Matão/SP e abarcava os jovens adultos e os adultos, de ambos os sexos, os quais vão "em família" ou "sozinhos". Já no Barreiro, a migração captada nas entrevistas, foi, majoritariamente, familiar e adulta, também de ambos os sexos. Enquanto que, por fim, na Várzea Queimada visualizamos uma migração predominantemente masculina e jovem, delineada pela divisão social do trabalho que ali se instaurou. Afinal, o trabalho artesanal com a folha de carnaúba é realizada exclusivamente pelas mulheres sendo ensinadas de mãe para filha.

Em síntese, temos que cada interior, ainda que seja uma comunidade rural e que apresente similitudes claras com os outros interiores, como o plantio de caju, feijão e mandioca, a divisão da tarefa do cultivo entre pais e filhos, a convivência de distintas gerações em um mesmo espaço e a configuração de uma cultura migratória (SILVA, 2008a e 2008b) comum que alicerça a dinâmica social do povoado, apresenta, entretanto, como vimos, particularidades claras em relação à sua dinâmica migratória e as trajetórias. Em Matão todos são piauienses; no Piauí, cada qual pertence à um interior ou à um bairrorural. 


\section{Considerações Finais}

A presença da população de trabalhadores rurais migrantes no interior do Estado de São Paulo se evidencia em decorrência de condicionantes socio-históricos que beneficiaram a RG de Araraquara e a configuração do município de Matão/SP como lócus privilegiado de atuação do agronegócio. Concomitantemente, a migração "permanentemente" temporária (SILVA, 2008a e 2008b) se apresenta como parte estruturante da dinâmica social da região de estudo, bem como, do local de origem. Além disso, observamos a convivência de distintos processos migratórios nos espaços de origem e de destino. Essa conjuntura corrobora para a percepção da migração como um evento demográfico mutável e multifacetado. Reforçamos, simultaneamente, a importância de estratégias de permanência ou deslocamento permeadas pelo acesso ao mercado de trabalho formal.

Buscamos, assim, tratar de novos espaços migratórios (BAENINGER, 2012) através da aplicabilidade da metodologia qualitativa para a compreensão do fenômeno social. Por fim, destacamos a necessidade de entendermos os locais de origem e de destino como partes integrantes e justapostas, particularmente, pelas transformações sociais, econômicas e demográficas ocorridas em ambos os espaços nos períodos da safra e da entressafra. É então necessário, apreendermos os processos vivenciados no tecido social das cidades e na vida desses migrantes, os quais constroem socialmente seu espaço migratório.

\section{Referências Bibliográficas}

ALVES, Francisco. Por que morre os cortadores de cana? Saúde e Sociedade, v. 15. N. 3. p. 90-98. Set/Dez 2006. São Paulo. Disponível em:< http://www.revistas.usp.br/sausoc/article/viewFile/7496/9009>. Acesso em Fev. de 2015.

BAENINGER, Rosana, Região Administrativa Central: Região de Governo de Araraquara e Região de Governo de São Carlos. Textos NEPO 31: Migração em São Paulo 7. Núcleo de Estudos de População/Unicamp. Campinas. 1995.

, Rosana. Espaço e Tempo em Campinas: Migrantes e a expansão do pólo industrial paulista. Coleção Campiniana. Unicamp. 1996. , Rosana. Deslocamentos Populacionais, Urbanização e Regionalização.

Revista Brasileira de Estudos Populacionais. Brasília. 15(2). 1998. , Rosana. Migrações internas no Brasil século 21: evidências empíricas e desafios conceituais. Mobilidade Espacial da População: Desafios teóricos e 
metodológicos par ao seu estudo. Cunha, José Marcos Pinto da (org). Núcleo de Estudos de População - Nepo/Unicamp. Campinas. 2011.

, Rosana, Fases e Faces da migração em São Paulo. Núcleo de Estudos de População -Nepo/Unicamp. Campinas. 2012.

CANO, Wilson. Perspectivas do Desenvolvimento Econômico do Interior Paulista. Modernização e Desenvolvimento no Interior de São Paulo. Tartaglia, José Carlos; Oliveira, Osvaldo Luiz de (orgs). Editora UNESP. São Paulo. 1988.

CORREAA, Roberto Lobato. Estudos sobre a rede urbana. Rio de Janeiro. Editora Bertrand Brasil. 2006.

DOMENACH, Hervé e PICOUET, Michel. Las Migraciones. Trad: Eduardo Bologna. Córdoba. República da Argentina. 1996.

ELIASa, Denise. Globalização e Agricultura. São Paulo. EdUSP. 2003.

Denise e Pequeno, Renato (orgs). Difusão do Agronegócio e Novas Dinâmicas Socioespaciais. Banco do Nordeste. Fortaleza. 2006.

, Denise e Pequeno, Renato. Desigualdades Socioespaciais nas Cidades do

Agronegócio. Anais do XII Encontro da Associação Nacional de Pós-Graduação e Pesquisa em Planejamento Urbano e Regional. Belém, 2007.

ELIASb, Norbert; SCOTSON, Jonh L. Os estabelecidos e os outsders: Sociologia da relações de poder a partir de uma pequena comunidade. Jorge Zahar.

MENEZES, Marilda A. Migrações: Uma Experiência Histórica do Campesinato do Nordeste. Diversidade do Campesinato: Expressões e Categorias. Vol II: Estratégias de Reprodução Social. De Godoi, E. P, Menezes, M. A e Marin, Rosa A (orgs) São Paulo. Editora Unesp. 2010.

, Marilda A. Migrações e Mobilidades: Repensando teorias, tipologias e conceitos. Migrações: Implicações passadas, presentes e futuras. Teixeira, P.E; Braga, A.M.C e Baeninger, R (org). Marília: Oficina Universitária. São Paulo: Cultura Acadêmica. 2012. 2000.

GONÇALVES, Maria Flora. As engrenagens da locomotiva: Ensaio sobre a formação urbana paulista. Tese de Doutorado. Instituto de Economia/Unicamp. Campinas. 1998. $339 \mathrm{p}$.

MACIEL, Lidiane Maria e BAENINGER, Rosana. Assalariamento Rural no interior de São Paulo: Um estudo sobre migrações e identidade. Anais do ${35^{\circ}}^{\circ}$ Encontro Anual da Associação de Pós-Graduação e Pesquisa em Ciências Sociais. Caxambu. 2011.

, Lidiane Maria. Migração e Identidade entre Trabalhadores "Rurais-Urbanos" no

interior de São Paulo. Anais do XI Congresso Luso Afro Brasileiro de Ciências Sociais. Salvador. 2011.

Lidiane Maria. O Sentido de Melhorar de Vida: Arranjos familiares na Migração Rural-Urbana para o interior de São Paulo. Jundiaí. Paco Editorial. 2013.

NEVES, Marcos Fava et al. O Retrato da Citricultura Brasileira. Markestrat. Ribeirão Preto. 2010.

PEREIRA, Giovana G; TROIANO, Jéssica A e MACIEL, Lidiane M. A heterogeneidade dos espaços rurais: Convivência e interdependência de agentes produtivos na região central 
do Estado de São Paulo (Brasil). Anais do IX Congresso da Associação LatinoAmericana de Sociologia Rural. Cidade do México. 2014.

SANTOS, Milton. Metamorfoses do Espaço Habitado: Fundamentos teóricos e metodológicos da Geografia. $6^{a}$ Edição. Editora da Universidade de São Paulo. [1988]

2012.

SILVA, Maria Aparecida de Moraes. Errantes do Fim do Século. São Paulo. Ed. UNESP. 1999.

Maria Aparecida de Moraes. Expropriação da terra, violência e migração: Camponeses maranhenses no corte da cana em São Paulo. Cadernos CERU (Versão Online). Vol. $\quad$ 19. $\quad \mathrm{N}^{\mathrm{o}} \quad 1 . \quad 2008 \mathrm{a}$ (Disponível em: http://www.revistas.usp.br/ceru/article/view/11851/13628 -Acesso em Maio/2011)

Maria Aparecida de Moraes. Expropriação da terra, violência e migração: Camponeses do nordeste do Brasil nos canaviais paulistas. Anais da 26a Região Brasileira de Antropologia. Porto Seguro. 2008b.

, Maria Aparecida de Moraes. Mortes e acidentes nas profundezas do mar de cana e dos laranjais paulistas. INTERFACEHS: Revista de Gestão Integrada em Saúde do Trabalho e Meio Ambiente. v.3. n. 2. Artigo 1. Abr/Agosto 2008. São Paulo.

Maria Aparecida; MELO, Beatriz e VERÇOSA, Lúcio Vasconcellos de Os (não direitos) dos trabalhadores rurais: "A permanência do intolerável". Cadernos Conflitos do Campo no Brasil. Comissão Pastoral da Terra. Brasília. 2011.

, Maria Aparecida e MELO, Beatriz. Vidas em Trânsito: Mulheres Migrantes dos Cocais Maranhenses nas Cidades Canavieiras Paulistas. Revista Tópos. Vol. 6. No.1. FCT-UNESP. Presidente Prudente. 2012.

SILVA, Virgínia Ferreira da Silva. Migração e redes sociais: Trajetórias, pertencimentos e relações sociais de migrantes no interior de São Paulo. Tese de Doutorado. Instituto de Filosofia e Ciências Sociais/UFRJ. Rio de Janeiro. 2006.

SINGER, Paul. Migrações Internas: Considerações Teóricas sobre o seu Estudo. Em Migração Interna(Textos Selecionados). De Moura, H. (coord.). Banco do Nordeste do Brasil S.A. - BND. Fortaleza. [1976] 1980.

VILLAÇA, Flávio. Espaço Intra-Urbano no Brasil. Studio Nobel. $2^{\text {a }}$ Edição. São Paulo. [2001] 2012.

VETORASSI, Andréa. Laços de Trabalho e Redes dos Migrantes: Um estudo sobre as dimensões objetivas e subjetivas presentes em redes sociais e identidades de grupos migrantes de Serrana-SP e Guariba-SP. Tese de Doutorado. Unicamp. 2010. 200p.

WANDERLEY, Maria de Nazareth Baudel. Um saber necessário: os estudos rurais no Brasil. Editora da Unicamp. Campinas. 2011. 